\title{
VITAMIN A AND CAROTENE. I. THE DETERMINATION OF VITAMIN A IN THE BLOOD AND LIVER AS AN INDEX OF VITAMIN A NUTRITION OF THE RAT
}

\author{
By PRISCILla B. HORTON, WILLIAM A. MURRILL, and ARTHUR C. CURTIS \\ (From the Department of Internal Medicine, University of Michigan, Ann Arbor) ${ }^{1}$
}

(Received for publication February 26, 1941)

Considerable interest has been evidenced during the past few years in the attempt to correlate the blood vitamin A content of the human under various conditions with the nutritional status of the body ( 1 to 6$)$. In these studies, normal ranges were determined by estimation of the blood vitamin $A$ for a large number of healthy subjects. In some instances $(1,4)$, human subjects were placed on vitamin A-deficient diets and the blood levels were followed over periods of two to six months. It was not possible to give diets entirely deficient in vitamin $\mathrm{A}$, or to continue the diets for sufficient lengths of time to reach critically low vitamin A levels. Because human subjects were used, it was also impossible to correlate the blood values with the liver stores. The present study, using the rat as the experimental animal, was designed to aid in the interpretation of data obtained on human subjects. Blood and liver vitamin A concentrations were determined on rats during the course of depletion and while they were fed definite quantities of vitamin $\mathrm{A}$.

\section{EXPERIMENTAL}

Eighty-six rats from a Wistar strain, twenty-eight days old, were placed on the basal diet given in Table $I$. Group I remained on the basal diet throughout the experiment. All animals in group II received the basal diet plus four units of vitamin A per day until the thirtyfifth day. At this point it was found that the body stores had been depleted. A part of this group was then reduced to zero units per day, a part remained on four units per day, and a part was raised to twenty units per day for the remainder of the experiment. Group III was depleted until loss of weight and incipient xerophthalmia indicated avitaminosis A. At this point each animal was given twenty units per day throughout the remainder of the experiment. Group IV was depleted in the same manner as group III. At the end of depletion each animal was given 1200 units of vitamin $A$ as a single dose, representing twenty units for each day on the depletion

1 The expense of this study was defrayed in part by a grant from the Horace H. Rackham and Mary A. Rackham Foundation. diet, and twenty units per day each day thereafter until the end of the experiment.

Throughout the experiment, groups of three, four, or five rats, depending on their size, were killed for analysis of the blood and liver at appropriate intervals. The pooled blood from each group was allowed to clot and the serum removed. Vitamin A determinations were run according to Kimbles' (5) modification of the method of Dann and Evelyn (7), using the macro unit of the Evelyn photoelectric colorimeter. The livers of each group of

TABLE I

Basal diet

\begin{tabular}{|c|c|c|}
\hline & Cotal weight & Total calories \\
\hline \multirow[t]{2}{*}{ 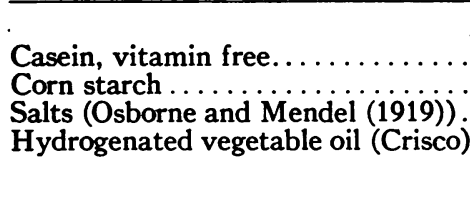 } & $\begin{array}{lc} & \text { per cent } \\
\cdots & 18 \\
\text {. } & 63 \\
\text { i) } & 15\end{array}$ & $\begin{array}{c}\text { per cent } \\
16 \\
55\end{array}$ \\
\hline & 100 & 100 \\
\hline
\end{tabular}

Vitamins B, G, and D were supplied daily in the form of pellets containing $400 \mathrm{mgm}$. of dried brewer's yeast and 10 I.U. of vitamin D as irradiated Ergosterol. : When a supplement of vitamin A was given, biologically standardized cod liver oil, diluted to furnish the desired number of International Units of vitamin A, was added to the pellets.

rats were similarly combined and weighed. They were then ground with anhydrous sodium sulfate until a fine powder was obtained. After making up to $100 \mathrm{cc}$. with water, and shaking well, $5 \mathrm{cc}$. aliquots of this viscous suspension were taken for analysis. Two cc. of 30 per cent $\mathrm{NaOH}$ were added to these samples, after which they were heated in a water bath under nitrogen for an hour, this being considered sufficient time to hydrolyze the esters of vitamin $A$ in the liver. The vitamin $A$ in the hydrolysate was then determined in a manner analogous to that applied to the blood samples.

The concentrations of vitamin $A$ in blopd and liver are expressed as micrograms per 100 te. of serum or 100 grams of liver tissue. To do thiss, the $L,(-1 \mathrm{~cm} ., 1$ per cent, $620 \mathrm{~m} \mu$ ) values obtained on the Bvelyn colorimeter and calculated according to Dän and Evelyn (7) are converted into the spectrophotometric extinction coefficient $E(1 \mathrm{~cm} ., 1$ per cent, $328 \mathrm{~m} \mu)$. The conversion factor, as determined by Dann and Evelyn, is $E(1 \mathrm{~cm} ., 1$ per cent, $\left.328 \mathrm{~m}^{\mu}\right)=L \times(0.41 \pm 0.05)$. Holmes and Corbet (8) have succeeded in preparing crystalline vitamin A 


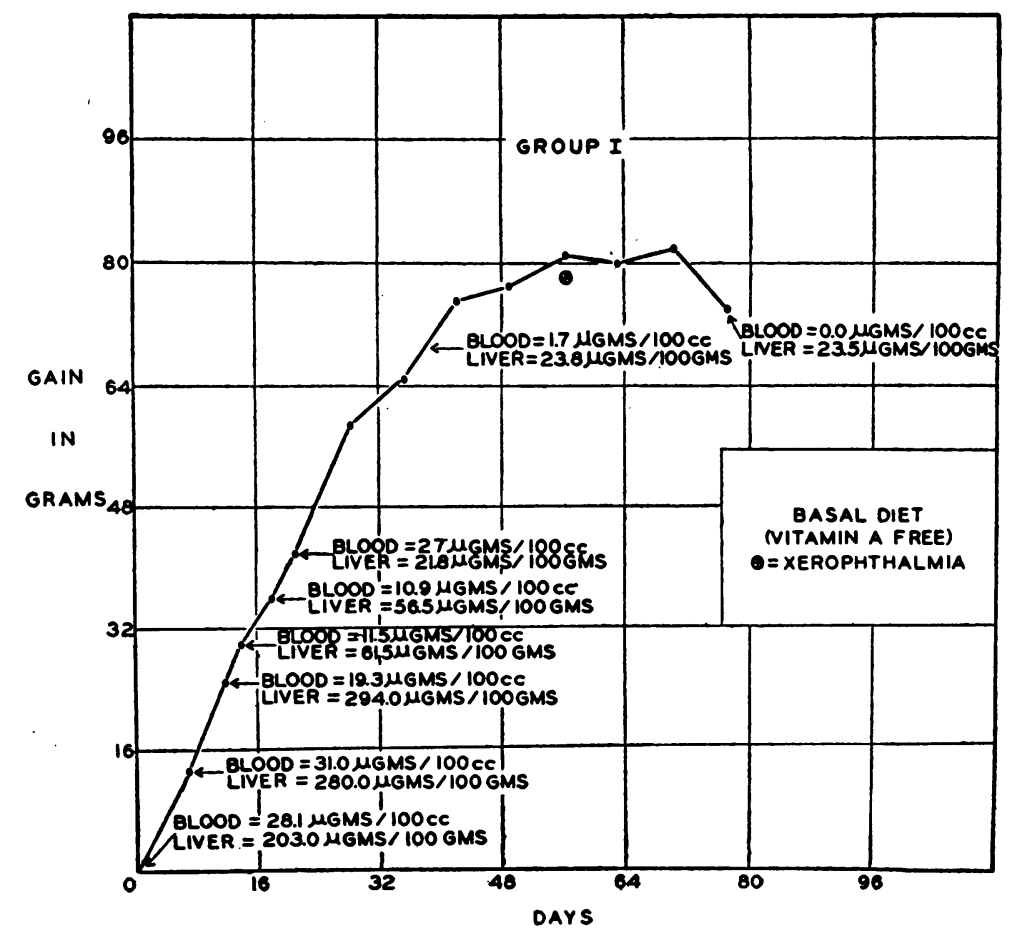

Fig. 1. Growth Curve and Concentrations of Vitamin A in the Blood and Liver of Rats Receiving No Vitamin A in Their Diet

from fish liver oil and have determined for their product that $E$ ( $1 \mathrm{~cm}$., 1 per cent, $328 \mathrm{~m} \mu)=2100$. Using this factor, it is possible to express our results in terms of vitamin A itself. The original $L$ value for all our determinations, as well as the micrograms of vitamin $A$ calculated from it, is given in Table II.

The crystalline vitamin A preparation of Holmes and Corbet was reported by them to have a biological value of $3,000,000 \pm 250,000$ International Units per gram. They now believe that this value is probably somewhat higher than 3,000,000 I. U. (9). These figures may be used to convert the $L$ value, which was obtained on our vitamin A concentrate in these experiments, to International Units. In this way the concentrate was calculated to contain 34,700 to $40,500 \mathrm{I}$. U. per gram, as compared with its biological estimation at 50,000 I. U. per gram.

\section{RESULTS AND DISCUSSION}

Figure 1 presents the growth curve of forty rats comprising group I. The diet of these animals contained no vitamin A. The vitamin A content of the blood and liver is inserted at the proper places. At the outset, on the seventh and on the eleventh day, the concentrations found in the blood and in the liver were within the range accepted as normal for young rats. Since so many rats were necessarily used to obtain sufficient amounts of blood for analysis, each group was likely to be made up of rats from a different litter. Hence the variations observed would be expected, since the initial concentrations of vitamin $\mathrm{A}$ in the liver would depend upon the mother's intake and how early the young started to eat the table scrap diet for themselves before being put on the experimental regime. The amounts of vitamin $\mathrm{A}$ in the liver of the young rats used in our work were, however, much lower than those found in older rats. Rats about a year old, who had been fed nothing but a table scrap diet, had as much as 9300 micrograms of vitamin A per 100 grams of liver. This explains why so much more time is required to deplete an adult rat than a young rat. Between the eleventh and fourteenth day there seemed to be an abrupt drop in the vitamin A concentration of both liver and blood. On the eighteenth day it was only slightly lower. By the twenty-first day a low vitamin A concentration, representing complete depletion, was attained and maintained until the last group, showing signs of xerophthalmia, was killed. It should be noted 
that vitamin A concentrations between 15 and 25 micrograms per 100 grams of liver were considered to represent complete depletion. The error introduced by extracted liver pigments makes the method less sensitive than it is for blood when vitamin $\mathrm{A}$ is low. As noted by Baumann, Riising and Steenbock (10), growth, in the absence of dietary or stored vitamin A, was surprisingly prolonged. It took three weeks only to deplete the liver and blood, but another five weeks elapsed before a definite cessation of growth and signs of xerophthalmia occurred. The abrupt drop in the liver stores between the eleventh and fourteenth days is striking. The concentrations in the blood paralleled those in the liver, but with a slight lag and with no abrupt falls. Both reached the depletion level at about the same time.
Figure 2 presents the growth curves of the twenty-two animals receiving the basal diet plus a daily supplement of four I.U. of vitamin A per day. When animals were killed for analysis on the thirty-fifth day, we were surprised to find that the blood and liver values had fallen to the depletion levels in spite of the daily supplement. Part of the remaining animals were then given twenty units of vitamin A per day. They maintained a normal growth curve until the end of the experiment. Analyses on the sixty-sixth day showed that the vitamin $\mathrm{A}$ of the blood had risen to an intermediate value but that of the liver had risen only a small amount; by the ninety-eighth day it had dropped again to the depletion level.

Similar results are present in Figure 3. In this experiment, twelve animals were depleted of vita-

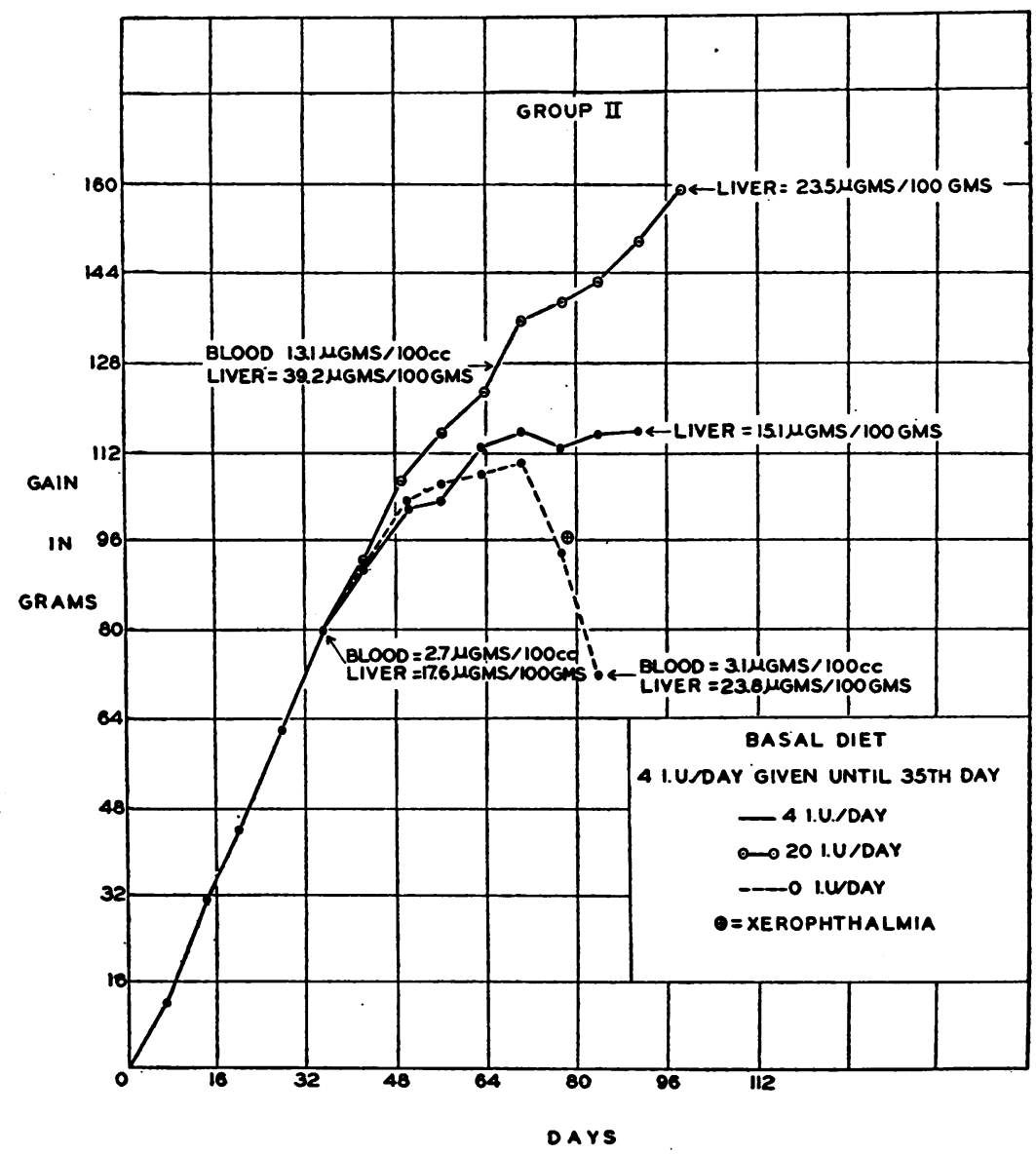

Fig. 2. Growth Curves and Concentrations of Vitamin A in the Blood and Liver of Rats Receiving Four I.U. Per Day Until the Thirty-fifth Day, Then Zero, Four, and Twenty I.U. Per Day, Respectively, Until the END OF THE EXPERIMENT 


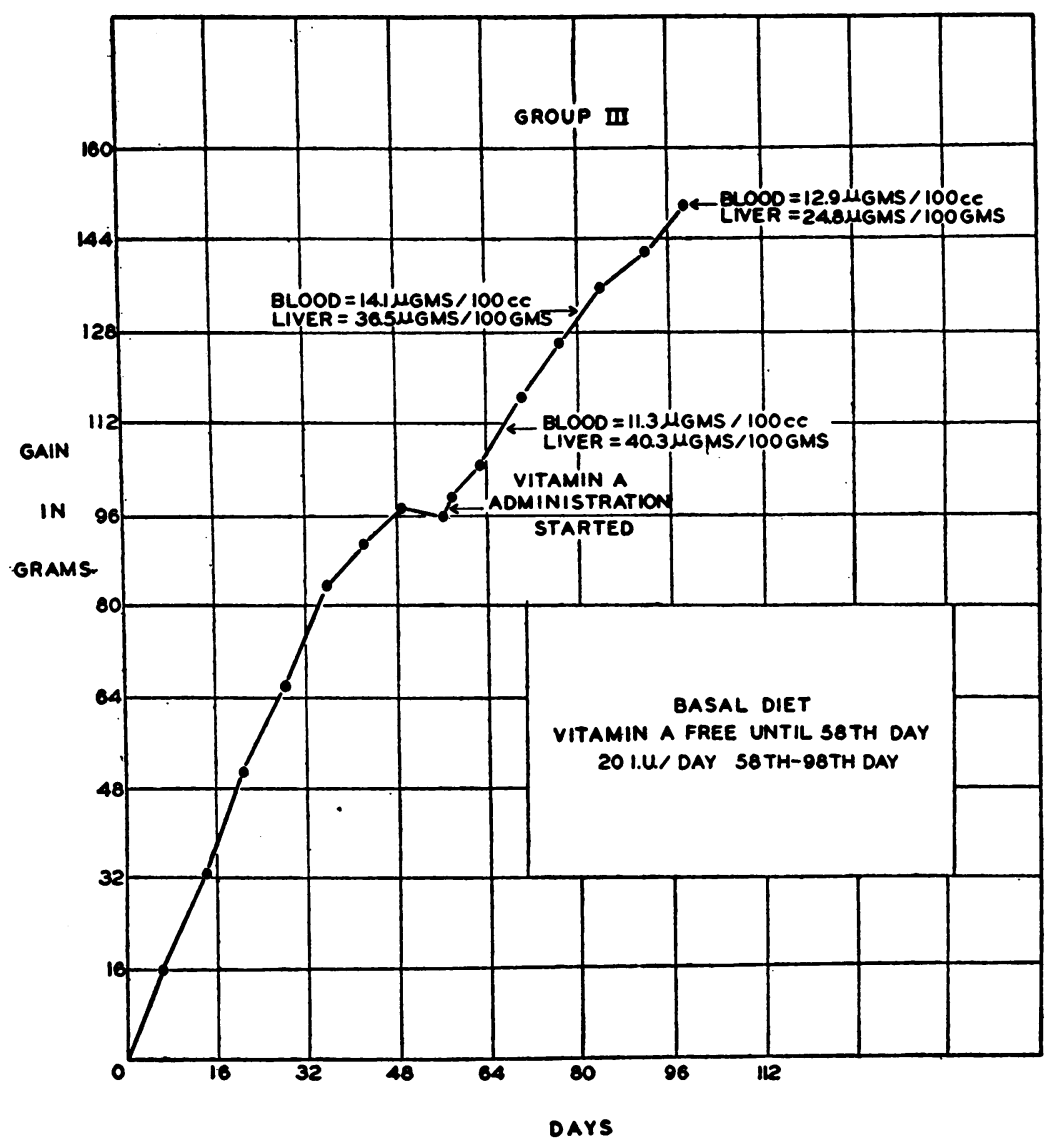

Fig. 3. Growth Curve and Concentrations of Vitamin A in the Blood and Liver of Rats Receiving No Vitamin A Until the Fifty-eighth Day, Then Twenty I.U. Per Day Thereafter Until the End of the Experiment

min A until growth ceased. At this point it was assumed that their blood and livers were depleted of vitamin A, as were those of the animals receiving an initial supplement of four I.U. per day, mentioned above. A daily supplement of twenty I.U. of vitamin A was begun and immediately normal growth was resumed. Here again the response is shown by a rise in the blood vitamin A, but there is little change in the liver. Apparently, twenty I.U. of vitamin A per day are sufficient to keep the blood concentrations high enough to maintain body functions but do not furnish enough to allow storage in the liver.

Of the rats receiving four I.U. of vitamin A per day until the thirty-fifth day (Figure 2), part were continued with the same dosage until the end of the experiment. The growth of these animals began to fall off by about the forty-ninth day. Though they did not actually lose weight, they did little more than maintain themselves. When they were killed on the ninety-first day, the livers were completely empty, as would be expected from the analysis of the livers on the thirty-fifth day.

The third curve in Figure 2 represents animals from whom vitamin $A$ was taken away altogether on the thirty-fifth day, after they had received four I.U. per day until this time. These rats were killed on the eighty-fourth day after loss of much weight and, as was expected, there was no vitamin $\mathrm{A}$ in the blood or liver. These animals had lost so much weight and were in such poor condition that they would certainly have died within a week if they had not been killed. It is also unlikely that the controls could have survived long beyond the seventy-seventh day when they were killed for analysis, since members of the group had already died, probably due to infection. Thus, the daily supplement of four I.U. of vitamin A received by 


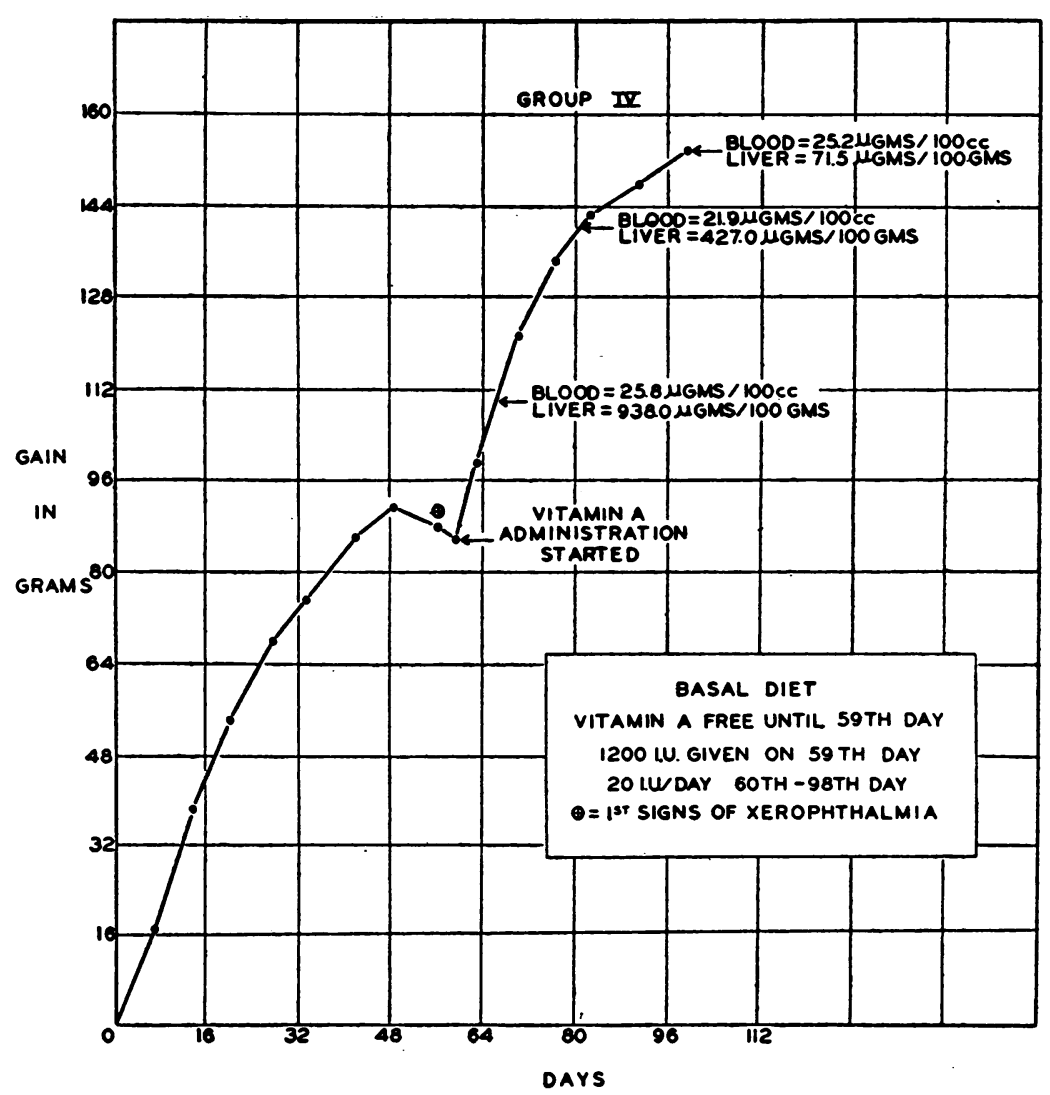

Fig. 4. Growth Curve and Concentrations of Vitamin A in the Blood and Liver of Rats Receiving No Vitamin a Until the Fifty-ninth Day, Then 1200 I.U. as a Single Dose and 20 I.U. Per Day Thereafter Until THE END OF THE EXPERIMENT

these rats for thirty-five days did not appear to prolong their lives beyond those of the controls who had received no supplement at all. Apparently, four I.U. of vitamin A daily had not slowed down depletion of the body stores appreciably. This is surprising since, by definition, one Sherman unit (approximately 1.4 I.U.) is sufficient to cure xerophthalmia and to produce slight growth. Anything above two I.U. has been generally accepted as enough to produce normal growth. Baumann, Riising, and Steenbock (10) found that as little as one I.U. was sufficient to cure xerophthalmia and restore growth but that seven to seventeen I.U. were required to produce storage in the liver. Goss and Guilbert (11) state that eighteen to twenty-two I.U. per day per $\mathrm{kgm}$. (about 1.8 to 2.2 I.U. for young rats) are necessary to prevent vaginal cornification, but they found no storage of the vitamin in the liver if less than 382 I.U. per day per $\mathrm{kgm}$. were given. We have shown in other experiments (12) that four I.U. daily are sufficient to cure xerophthalmia and cause the rat to resume normal growth at least for a short period, but unreported determinations on these rats show that this amount does not raise the concentration in the blood above the depletion level. The present experiment shows that four I.U. are enough only to maintain body weight and protect against xerophthalmia, but furnish no vitamin $\mathrm{A}$ to the blood or liver as a margin of safety for the animal.

Figure 4 presents the growth curve for twelve rats which, at the end of the depletion period, received 1200 I.U. of vitamin $A$ as a single dose, representing twenty I.U. per day for each day or the depletion diet, and thereafter received twenty I.U. per day. Here again normal growth was resumed. Rats killed seven days after the initial administration showed a large liver reserve and a normal blood value. Sixteen days later, however, 


\begin{tabular}{|c|c|c|c|c|c|}
\hline & \multicolumn{5}{|c|}{ Vitamin A } \\
\hline & \multicolumn{2}{|l|}{ Blood } & \multicolumn{2}{|l|}{ Liver } & \multirow{2}{*}{$-\left.\right|_{\text {Liver fat }} ^{\text {grams }}$} \\
\hline & $\begin{array}{c}L(1 \mathrm{per} \text { cent } 1 \mathrm{~cm} .) \\
\times 10^{3}\end{array}$ & $\left|\begin{array}{c}\text { micro- } \\
\text { grams } \\
\text { per cent }\end{array}\right|$ & $\begin{array}{c}L(1 \text { per cent } 1 \mathrm{~cm} .) \\
\times 10^{3}\end{array}$ & $\mid \begin{array}{c}\text { micro- } \\
\text { grams } \\
\text { per cent }\end{array}$ & \\
\hline 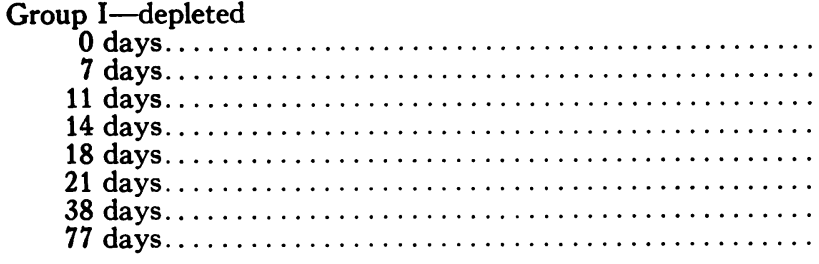 & $\begin{array}{l}1.44 \\
1.59 \\
0.99 \\
0.59 \\
0.56 \\
0.14 \\
0.09 \\
0.0\end{array}$ & \begin{tabular}{r|}
28.1 \\
31.0 \\
19.3 \\
11.5 \\
10.9 \\
2.7 \\
1.7 \\
0.0
\end{tabular} & $\begin{array}{r}10.40 \\
14.35 \\
15.06 \\
3.15 \\
2.89 \\
1.12 \\
1.22 \\
1.21\end{array}$ & $\begin{array}{r}203.0 \\
280.0 \\
294.0 \\
61.5 \\
56.5 \\
21.8 \\
23.8 \\
23.5\end{array}$ & $\begin{array}{r}6.25 \\
8.02 \\
5.84 \\
10.05 \\
13.80 \\
8.30\end{array}$ \\
\hline $\begin{array}{l}\text { Group II-Four I.U. vitamin A per day to thirty-fifth day } \\
\text { Thirty-fifth day. } \\
20 \text { units per day thirty-fifth to sixty-sixth day } \ldots \ldots \ldots \ldots \\
20 \text { units per day thirty-fifth to ninety-eighth day } \ldots \ldots \ldots \\
4 \text { units per day thirty-fifth to eighty-fourth day } \ldots \ldots \ldots \\
0 \text { units per day thirty-fifth to eighty-fourth day } \ldots \ldots \ldots\end{array}$ & $\begin{array}{l}0.14 \\
0.67 \\
0.16\end{array}$ & $\begin{array}{r}2.7 \\
13.1\end{array}$ & $\begin{array}{l}0.90 \\
2.01 \\
1.20 \\
0.77 \\
1.22\end{array}$ & $\begin{array}{l}17.6 \\
39.2 \\
23.5 \\
15.1 \\
23.8\end{array}$ & $\begin{array}{l}11.25 \\
14.55\end{array}$ \\
\hline $\begin{array}{l}\text { Group III - depleted to fifty-eighth day } \\
20 \text { units per day to sixty-seventh day } \ldots \ldots \ldots \ldots \ldots \ldots \ldots \ldots \ldots \ldots \ldots \\
20 \text { units per day to eighty-first day } \ldots \ldots \ldots \ldots \ldots \ldots \ldots \ldots \\
20 \text { units per day to ninety-eighth day } \ldots \ldots \ldots \ldots \ldots \ldots\end{array}$ & $\begin{array}{l}0.58 \\
0.72 \\
0.66\end{array}$ & $\begin{array}{l}11.3 \\
14.1 \\
12.9\end{array}$ & $\begin{array}{l}2.06 \\
1.85 \\
1.27\end{array}$ & $\begin{array}{l}40.3 \\
36.1 \\
24.8\end{array}$ & $\begin{array}{l}19.35 \\
17.40\end{array}$ \\
\hline $\begin{array}{l}\text { Group IV-depleted to fifty-ninth day-1200 I.U. vitamin A } \\
\text { given as one dose } \\
20 \text { units per day to sixty-sixth day } \ldots \ldots \ldots \ldots \ldots \ldots \ldots \ldots \ldots \ldots \ldots \ldots \ldots \\
20 \text { units per day to eighty-second day } \ldots \ldots \ldots \ldots \ldots \ldots \ldots \\
20 \text { units per day to ninety-eighth day } \ldots \ldots \ldots \ldots \ldots\end{array}$ & $\begin{array}{l}1.32 \\
1.12 \\
1.29\end{array}$ & $\begin{array}{l}25.8 \\
21.9 \\
25.2\end{array}$ & $\begin{array}{r}48.00 \\
21.80 \\
3.66\end{array}$ & $\begin{array}{r}938.0 \\
427.0 \\
71.5\end{array}$ & 14.85 \\
\hline
\end{tabular}

the concentration in the liver had gone down by more than one-half, and on the thirty-ninth day after the administration the liver was nearly depleted of vitamin A. The concentration in the blood in each instance remained normal. Throughout this time the liver had been furnishing a decreasing vitamin A supply, but this plus the dietary supplement was sufficient to maintain a normal concentration in the blood. These values indicate that even twenty units per day, though they support normal growth, are not sufficient to maintain the liver stores. At the end of the experiment these animals were little better off than those shown in Figure 3 who had not received the massive dose at the end of depletion. In view of the findings of Baumann et al (10), twenty I.U. of vitamin A per day seemed to us a liberal amount. The fact that they were not enough to maintain liver storage was surprising. Work is now in progress on the vitamin A requirement for normal liver storage.

Table II summarizes the material in the charts, giving the vitamin A concentration both in $L$ units and in micrograms per $100 \mathrm{cc}$. of material used. Determinations on the fat content of the livers are also included. We wished to find out whether there was any change in fat content, paralleling the changes in vitamin A. However, we could find no such parallelism. This confirmed the observations of Thorbjarnarson and Drummond (13).

From the above data, it seems fair to conclude that determinations of the concentration of vitamin $\mathrm{A}$ in blood are an index to the vitamin $\mathrm{A}$ nutrition of the body in the rat. There is definitely a relationship between the concentration in the blood and the liver stores. A normal blood concentration cannot be maintained unless there is adequate liver storage. As the liver stores are depleted, the concentration in the blood gradually decreases, since intermediate concentrations are found in the blood when the liver stores are low. Complete absence of vitamin $\mathrm{A}$ in the blood and in the liver occurs at about the same time. In cases of suboptimal intake, the concentration in the blood is especially significant. Apparently, if it is maintained above a certain minimum, the 
tissues are furnished with sufficient vitamin A for continued growth and development. When this concentration cannot be maintained from the diet or liver stores, the animal starts to lose weight and to develop characteristic avitaminosis A symptoms. These, however, occur as very late manifestations of low blood and liver concentrations. Even when the animal has been shown by chemical analysis to be depleted of vitamin $A$, there is a long and unexplained lag in the physiological response.

\section{SUM MARY}

1. A total of eighty-six rats, twenty-eight days old, were placed on basal diets containing no vitamin A. Part were given supplements of a definite amount of the vitamin at the beginning of the experiment, and part were given none throughout. The rest were depleted of vitamin A, then divided into groups, each group receiving different amounts of vitamin A. Animals were killed at intervals during the experiment and the vitamin $A$ content of the livers and blood was determined.

2. When no vitamin A was included in the diet, its concentration in the blood and liver declined in a parallel manner. Animals receiving four I.U. per day showed depletion levels in the blood and liver at approximately the same time as those receiving no supplement. Twenty I.U. per day were not sufficient to maintain storage in the liver, but did maintain an elevated (though subnormal) concentration in the blood. These animals grew normally.

3. It is concluded that determinations of the concentration of vitamin $\mathrm{A}$ in the blood are an index of the vitamin A nutrition of the body.

Since this paper was accepted for publication, J. M. Lewis and others have published data which for the most part confirm the findings presented here (14).

\section{BIBLIOGRAPHY}

1. Steininger, G., Roberts, L. J., and Brenner, S., Vita $\min \mathrm{A}$ in the blood of normal adults: The effecr of a depletion diet on blood values and biopho tometer readings. J. A. M. A., 1939, 113, 2381.

2. May, C. D., and others, Clinical studies on vitamin $A$ in infants and in children. Am. J. Dis Child., 1940, 59, 1167.

3. Pett, L. B., and LePage, G. A., Vitamin A deficiency. III. Blood analysis correlated with a visual test. J. Biol. Chem., 1940, 132, 585.

4. Murrill, W. A., Horton, P. B., Leibermann, E., and Newburgh, L. H., Vitamin A and carotene metabolism in diabetics and normals. (To be published.)

5. Kimble, M. S., The photocolorimetric determination of vitamin $\mathrm{A}$ and carotene in human plasma. J. Lab. and Clin. Med., 1939, 24, 1055.

6. Lindquist, T., Studien über das Vitamin A beim Menschen. Acta Med. Scandinav., 1938, Suppl. 97.

7. Dann, W. J., and Evelyn, K. A., The determination of vitamin $\mathrm{A}$ with the photoelectric colorimeter. Biochem. J., 1938, 32, 1008.

8. Holmes, H. N., and Corbet, R. E., The isolation of crystalline vitamin $A^{1}$. J. Am. Chem. Soc., 1937, 59, 2042.

9. Holmes, H. N., Personal communication.

10. Baumann, C. A., Riising, B. M., and Steenbock, H., Fat-soluble vitamins. XLII. The absorption and storage of vitamin A in the rat. J. Biol. Chem., 1934, 107, 705.

11. Goss, H., and Guilbert, H. R., The minimum vitamin $A$ and carotene requirements of the rat. J. Nutrition, 1939, 18, 169.

12. Curtis, A. C., and Horton, P. B., The utilization of vitamin $\mathrm{A}$ added to mineral oil. Am. J. M. Sc., 1940, 200, 102.

13. Thorbjarnarson, T., and Drummond, J. C., Conditions influencing the storage of vitamin $\mathrm{A}$ in the liver. Biochem. J., 1938, 32, 5.

14. Lewis, J. M., and others, Relationship of vitamin A blood level in the rat to vitamin A intake and to liver storage. Proc. Soc. Exper. Biol. and Med., 1941, 46, 248. 